\title{
Impact of Annual Exposure to Polycyclic Aromatic Hydrocarbons on Acute Exacerbation Frequency in Asthmatic Patients
}

This article was published in the following Dove Press journal: Journal of Asthma and Allergy

\begin{abstract}
Shih-Wei Lee, ${ }^{\text {I, } * \text { Yu- }}$ Chen Huang, iD $^{2,3, *}$ ChunYu Lin, ${ }^{2,3}$ Hung-Yu Huang, ${ }^{2,3}$ ChiWei Liu,' Ming-Tsuen Hsieh, (D) ${ }^{4}$ Chon-Lin Lee, ${ }^{4-7}$ Wen-Yu Chung, ${ }^{8}$ Kian Fan Chung, ${ }^{9}$ ChunHua Wang, (iD) ${ }^{2,3}$ Han-Pin Kuo ${ }^{10,11}$

'Department of Internal Medicine, Taoyuan General Hospital, Ministry of Health and Welfare, Taoyuan, Taiwan; ${ }^{2}$ Department of Thoracic Medicine, Chang Gung Memorial Hospital, Taipei, Taiwan; ${ }^{3}$ College of Medicine, Chang Gung Memorial University, Taoyuan, Taiwan; ${ }^{4}$ Department of Marine Environment and Engineering, National Sun Yat-Sen University, Kaohsiung, Taiwan; ${ }^{5}$ Aerosol Science and Research Center, National Sun Yat-Sen University, Kaohsiung, Taiwan; ${ }^{6}$ Department of Public Health, Kaohsiung Medical University, Kaohsiung, Taiwan; ${ }^{7}$ Department of Applied Chemistry, Providence University, Taichung, Taiwan; ${ }^{8}$ Department of Computer Science and Information Engineering, National Kaohsiung University of Science and Technology, Kaohsiung, Taiwan; ' ${ }^{9}$ Experimental Studies, National Heart and Lung Institute, Imperial College London and Royal Brompton Hospital, London, UK; ${ }^{10}$ Pulmonary Medicine Research Center, Taipei Medical University, Taipei, Taiwan; "'Department of Thoracic Medicine, Taipei Medical University Hospital, Taipei, Taiwan

*These authors contributed equally to this work
\end{abstract}

Correspondence: Chun-Hua Wang Department of Thoracic Medicine, Chang Gung Memorial Hospital, 199 Tun-Hwa

North Road, Taipei 10507, Taiwan

Tel +886332I 1200 ext 8467

Email wchunhua@ms7.hinet.net

Han-Pin Kuo

Department of Medicine, Taipei Medical

University School of Medicine, 250 Wu-Xing

Street, Taipei II03I, Taiwan

Email q8828@ms I I.hinet.net
Purpose: Exposure to polycyclic aromatic hydrocarbons (PAHs) associated with ambient air particulate matter (PM) poses significant health concerns. Increased acute exacerbation (AE) frequency in asthmatic patients has been associated with ambient PAHs, but which subgroup of patients are particularly susceptible to ambient PAHs is uncertain. We developed a new model to simulate grid-scale $\mathrm{PM}_{2.5}$-PAH levels in order to evaluate whether the severity of asthma as measured by the Global Initiative of Asthma (GINA) levels of treatment is related to cumulative exposure of ambient PAHs.

Methods: Patients with asthma residing in the northern Taiwan were reviewed retrospectively from 2014 to 2017. $\mathrm{PM}_{2.5}$ were sampled and analysed for PAHs twice a month over a 72-hour period, in addition to collecting the routinely monitored air pollutant data from an established air quality monitoring network. In combination with correlation analysis and principal component analysis, multivariate linear regression models were performed to simulate hourly grid-scale $\mathrm{PM}_{2.5} \mathrm{PAH}$ concentrations $\left(\mathrm{ng} / \mathrm{m}^{3}\right)$. A geographic information system mapping approach with ordinary kriging interpolation method was used to calculate the annual exposure of PAHs (ng/m).

Results: Among the 387 patients with asthma aged 18 to 93 (median 62), 97 subjects were treated as GINA step 5 (24\%). Asthmatics in GINA 5 subgroup with high annual PAHs exposure were likely to have a higher annual frequency of any $\operatorname{AE}(1(0-12), p<0.0001)$. Annual PAHs exposure was correlated with the annual frequency of any exacerbation $(\mathrm{r}=0.11, \mathrm{p}=0.02)$. This was more significant in the GINA 5 subgroup $(\mathrm{r}=0.29, \mathrm{p}=0.005)$ and in the GINA 5 subgroup with severe acute exacerbations $(r=0.51, p=0.002)$. Annual PAHs exposure, severe acute exacerbation and GINA steps were independent variables that predict annual frequency of any exacerbation.

Conclusion: Asthmatic patients in the GINA 5 subgroup with acute exacerbations were more susceptible to the effect of environmental PAHs on their exacerbation frequency. Reducing environmental levels of PAHs will have the greatest impact on the more severe asthma patients.

Keywords: polycyclic aromatic hydrocarbons, asthma acute exacerbation, GINA, hourly grid-scale model

\section{Introduction}

Exposure to polycyclic aromatic hydrocarbons (PAHs) associated with ambient air particulate matter (PM) poses significant health concerns. ${ }^{1,2}$ According to the World Health Organization (WHO) ambient air pollution database, it is the fifth leading risk factor for mortality worldwide and continues to be a global problem affecting 
people in urban areas. ${ }^{3}$ Polycyclic aromatic hydrocarbons, mainly from incomplete combustion of fossil fuels and coals, ${ }^{4}$ can bind to particulate matter to enter into the human body through the respiratory system, ${ }^{5}$ and accumulate in the tracheobronchial and alveolar epithelium, through which they can enter the circulatory system. ${ }^{6,7}$ PAHs may cause oxidative injury to the airways, leading to inflammation, remodeling, and an increased risk of allergic sensitization; ${ }^{8-10}$ in addition, they may increase the incidence and worsen pulmonary diseases such as chronic pulmonary obstructive lung disease, ${ }^{11}$ lung cancer, ${ }^{12}$ and asthma. ${ }^{13,14}$

Asthma, a common chronic inflammatory airways disease, is characterized by airway hyperresponsiveness, ${ }^{15}$ and is particularly susceptible to ambient air pollutants which have been associated with an increase in acute exacerbation frequency. Exposure to traffic-related air pollutants such as fine particulate matter of $2.5 \mu \mathrm{m}$ or less in diameter $\left(\mathrm{PM}_{2.5}\right)$ during childhood also may favor the development of asthma as well as having a deleterious effect on the asthmatic state in children. ${ }^{16}$ Acute exacerbations needing emergency room visits ${ }^{17-19}$ and hospital admissions ${ }^{20,21}$ are increased in asthmatic patients following high levels of ambient air pollutant. Exposure to PAHs, which is a major component of fine particulate matter of air pollution, may induce oxidative stress and airway inflammation, and increase asthma exacerbations. ${ }^{22-24}$ Although the link between ambient air pollutants and asthma exacerbations has been highlighted, it is not known which subgroup of asthmatic patients are particularly affected by long-term exposure to PAHs. Asthma disease severity based on Global initiative of asthma (GINA) step treatment has been associated with an increasing rate of acute exacerbations. ${ }^{25}$ Therefore, the objective of our study was to evaluate whether the severity of asthma as measured by the GINA level of treatment needed is related to the long-term cumulative exposure of yearly ambient levels of PAHs. We used a recently developed grid-scale model to simulate the hourly spatiotemporal distribution of $\mathrm{PM}_{2.5}$-PAHs and to derive an annual cumulative exposure to PAHs. ${ }^{26}$ We hypothesized that increasing annual cumulative exposure to PAHs would be associated with a greater frequency of any acute exacerbations in the more severe patients with asthma.

\section{Methods}

\section{Study Subjects}

From January 2014 to December 2017, 477 patients who fulfilled the criteria of American Thoracic Society (ATS) for asthma at Chang Gung Memorial Hospital (CGMH) and Taoyuan General Hospital, Ministry of Health and Welfare $(\mathrm{TYGH}),{ }^{27}$ were retrospectively reviewed. Inclusion criteria were (1) $\geq 18$-years of age (2) receiving regular treatment of anti-asthma medication for more than 1 year (3) a record of reversibility of forced expiration volume in the first second $\left(\mathrm{FEV}_{1}\right.$ ) (an increase in $\mathrm{FEV}_{1}$ of $\geq 12 \%$ and $200 \mathrm{~mL}$ spontaneously after inhaled shortacting $\beta_{2}$ agonists) and (4) the patients lived in Taoyuan city, Taipei city, or New Taipei city in Taiwan. Patients with the following diseases, such as malignancy, bronchiectasis, chronic obstructive pulmonary disease, active respiratory inflammatory of infectious diseases (pulmonary tuberculosis or pneumonia), connective tissue diseases, unstable cardiovascular diseases (coronary artery disease, congestive heart disease, etc.) and active major systemic diseases (liver, renal, metabolism, etc.) were excluded. Asthma treatment was classified according to GINA 2017 treatment steps, ${ }^{28}$ as follows: Treatment step1: As needed inhaled short-acting beta 2 agonist (SABA). Treatment step2: Regular inhaled corticosteroids (ICS) plus as-need SABA. Treatment step3: Maintenance low dose of ICS with LABA plus as-need SABA. Treatment step4: Maintenance medium to high dose ICS with LABA plus as-need SABA. Treatment step5: Maintenance medium to high dose ICS with LABA, and/or add-on longacting anticholinergic antagonist (LAMA) or anti-IgE, and/or oral corticosteroids (OCS) maintenance or asneeded. Compliance to medication was also recorded. Twenty-three patients were excluded because they did not live in the aforementioned areas. Sixty-seven patients were excluded because they were not under regular asthmatic medicine control for more than one year. The remaining 387 patients were eligible for the analysis (Figure 1). The Institution Review Board of Chang Gung Memorial Hospital approved the study according with the Declaration of Helsinki (IRB Number: 201601021B0). The IRB determined that written informed consent was waived due to the retrospective nature of this study, along with no modifications in patient management. All personal information was encrypted in the database, and patient data access was de-identified.

\section{Subgroup Definition}

The home address, clinical profiles, allergic status, severity of asthma based on GINA guidelines, and severity and frequency of acute exacerbation were recorded. Atopic status was assessed by an automated immunoassay testing 


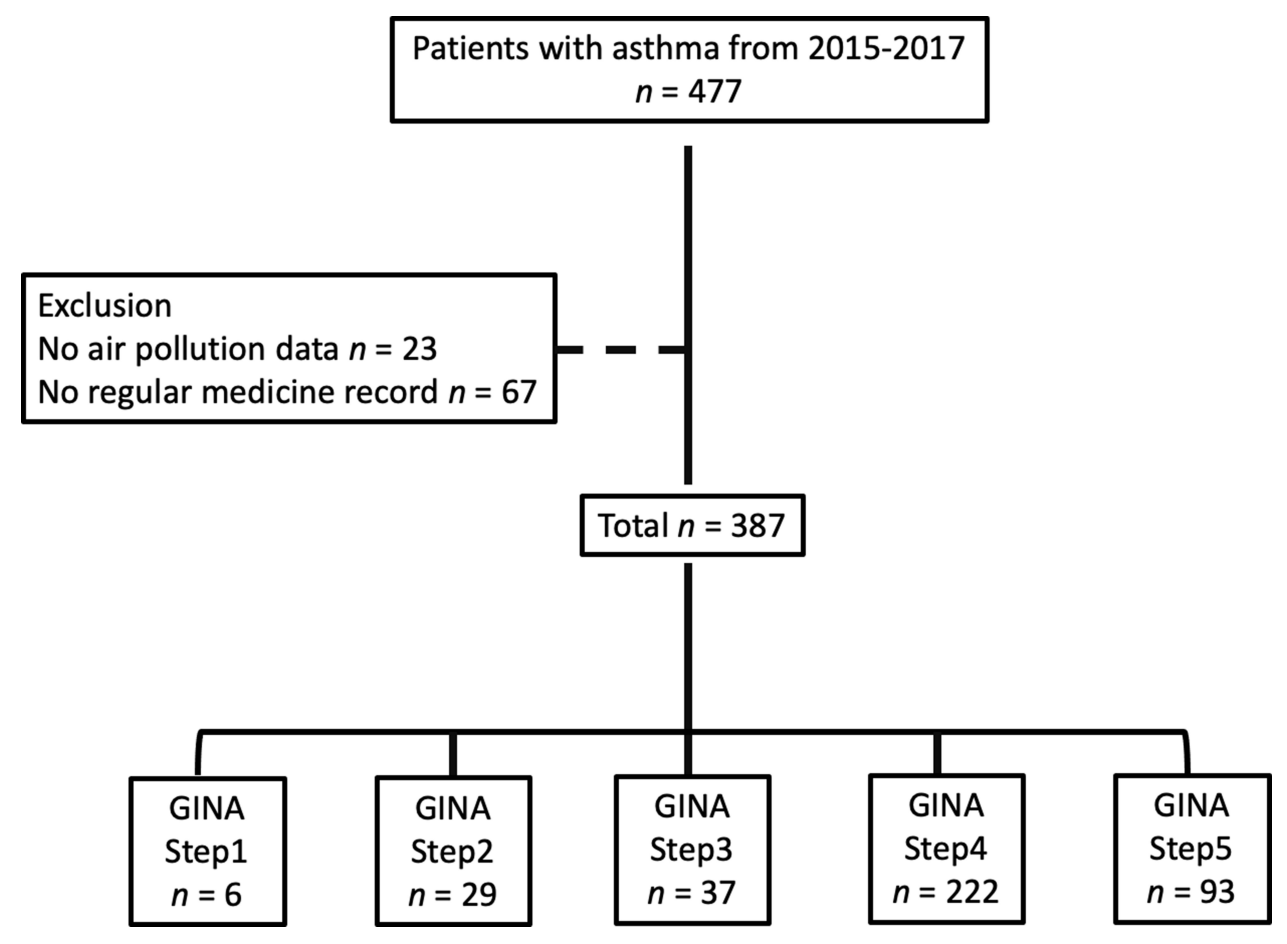

Figure I Flow chart of the enrolled patients.

by ImmunoCAP (Phadia Laboratory Systems, Uppsala, Sweden) for total $\operatorname{IgE}(\mathrm{KU} / \mathrm{L})$ and specific $\operatorname{IgE}$ antibodies to common allergens (house dust mite mix, grass mix, mold mix, animal epithelia mix). Positive atopic status was defined as any positive ImmunoCAP test for allergen-specific $\operatorname{IgE}(>0.35 \mathrm{KU} / \mathrm{L}) .{ }^{29,30}$ Mild acute exacerbation was defined as increased usage of inhaled corticosteroids without moderate or severe exacerbation. Moderate acute exacerbation was defined as needing oral steroids or antibiotics when assessed in the clinic. Severe acute exacerbation includes an event when the patient had to visit the emergency department or has been hospitalized due to respiratory distress. ${ }^{31}$ The index of acute exacerbation severity was scored as one in patients experiencing a severe acute exacerbation; otherwise, the index was zero. Patients were grouped by GINA step 1 to step 5 according to the GINA guidelines of $2017 .^{28}$

\section{A Grid-Scale Model for Simulating Hourly $\mathrm{PM}_{2.5}$-PAH Concentrations}

To build the hourly $\mathrm{PM}_{2.5}$-PAH grid-scale model, the dataset was collected from 2014 to 2017 in Taipei city, New Taipei city and Taoyuan city and treated with multivariate linear regression (MLR) model for $\mathrm{PM}_{2.5}$-PAH concentration simulation and a geographic information system (GIS) mapping approach with ordinary kriging (OK) interpolation method.
Detailed information of the model simulation method has been previously reported. ${ }^{26,32}$ Briefly, the 72-hour particle samples were collected by a portable air sampler twice a month at six sampling sites (as shown in Figure 2) and the routinely monitored air pollutant data/meteorological data (eg, $\mathrm{CO}, \mathrm{PM}_{2.5}$, $\mathrm{PM}_{10}, \mathrm{NO}_{\mathrm{x}}$, wind speed, relative humidity and ambient temperature) were collected from Taiwan Environmental Protection Administration (TEPA) monitoring stations nearby. After extracting and analysing the PAHs concentration by GC-

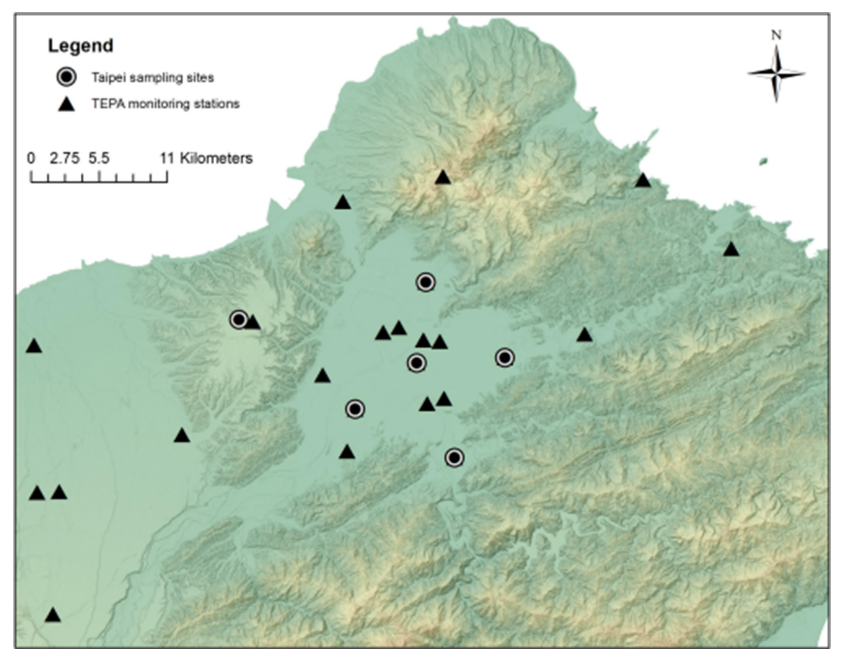

Figure 2 Sampling sites that were located nearby Taiwan Environmental Protection Administration (TEPA) monitoring stations. 
MS, we applied correlation analysis, principal component analysis (PCA), and stepwise regression approach to determine the predominant sources (eg, vehicle emissions or coal/ wood combustion) and predictors of PAHs concentration. Using these datasets and predictors including ambient temperature, $\mathrm{CO}, \mathrm{NOx}$, and $\mathrm{PM}_{10}$, an hourly grid-scale model was constructed by MLR for simulation of $\mathrm{PM}_{2.5}$-PAH concentration. Then, a GIS mapping approach with $\mathrm{OK}$ interpolation method was used to estimate the hourly $\mathrm{PM}_{2.5}$-PAH concentration of the patient cases and illustrate the spatial variation of $\mathrm{PM}_{2.5}$-PAHs concentrations. The hourly grid-scale model was then applied to calculate each patient's yearly cumulative PAH exposure at his/her home address.

\section{Statistical Analysis}

We used Mann-Whitney and Kruskal-Wallis analysis to determine the statistical significance of differences between groups, and Wilcoxon matched-paired test was used to determine within-group differences. Fisher's exact tests were used to determine the significance differences between groups in terms of gender and smoking status. Pearson's correlation was used to examine the correlation and multivariable regression analysis was used to determine the independent parameters that predict annual exacerbation frequency. At each step, variables with a significant relationship with annual exacerbation frequency (defined as $\mathrm{p} \leq 0.05$ ) were considered for adding to or removing from the set of explanatory variables following a sequence of F-tests (addition if $\mathrm{p}<0.05$ and removal if $\mathrm{p}>0.10$ ) in multivariable regression analysis by stepwise method. Normally distributed values were expressed as mean $\pm \mathrm{SE}$, whereas medians and ranges were used to describe skewed distributed data. All reported $\mathrm{P}$ values were two-sided, with $\mathrm{p}<0.05$ considered statically significant. All data were analyzed using $\mathrm{R}$ version 3.5.2 ( $\mathrm{R}$ foundation for statistical computing)

\section{Results}

\section{Baseline Characteristics of Subjects}

The 387 patients with asthma include 207 male (53.4\%) and 90 smokers or ex-smokers $(23.3 \%)$. Two hundred and forty-one $(63.3 \%)$ patients were atopic. Those who experienced asthma exacerbations included 166 (42.9\%) no/ mild, 89 (23.0\%) moderate and 132 (34.1\%) severe acute exacerbations from 2014 to 2017, respectively. Current treatment of asthma included $6(1.6 \%)$ GINA step1, 29 (7.5\%) GINA step2, 37 (9.6\%) GINA step3, 222 (57.4\%)
GINA step4, and 93 (24\%) GINA step5. The median annual frequency of any acute exacerbation was 0.3 (0-12) (time/year) and the annual PAHs concentration was $1.1(0.7-2.4)\left(\mathrm{ng} / \mathrm{m}^{3} /\right.$ year) (Table 1$)$.

\section{Clinical Characteristics of GINA Step Treatment Subgroups}

Patients with asthma in GINA step5 treatment were older, predominantly male, had a greater smoking history, associated with lower pulmonary function, and experienced more severe acute exacerbations as well as a higher annual any exacerbation frequency compared to the other GINA subgroups (Table 2). Otherwise, there was no significant difference of BMI, atopic status, IgE level, the proportion

Table I Clinical Characteristics of All Asthma Participants

\begin{tabular}{|c|c|}
\hline Variables & Total $(n=387)$ \\
\hline $\begin{array}{l}\text { Age, years } \\
\text { Gender, male (n, \%) } \\
\text { Current/ever smokers }(\mathrm{n}, \%) \\
\text { BMI }\left(\mathrm{kg} / \mathrm{m}^{2}\right) \\
\text { Atopic }(\mathrm{n}, \%) \\
\text { IgE level }(\mathrm{IU} / \mathrm{mL}) \\
\text { Non-compliance of medication, }(\mathrm{n}, \%)\end{array}$ & $\begin{array}{l}62(18-93) \\
207(53.4) \\
90(23.3) \\
24.6(16.6-38.1) \\
24 I(63.3) \\
111(0-5000) \\
116(34.1)\end{array}$ \\
\hline $\begin{array}{l}\text { Pulmonary function test } \\
\text { FVC (L) } \\
\text { FVC (\% predicted) } \\
\text { FEV , (L) } \\
\text { FEV I (\%predicted) }_{\text {FEV / FVC ratio (\%) }}\end{array}$ & $\begin{array}{l}2.2(0.4-5.1) \\
76(15-61) \\
1.5(0.3-4.2) \\
69(17-156) \\
71.1(24-100)\end{array}$ \\
\hline $\begin{array}{l}\text { Annual change of FEV } \text { (\%) } \\
\text { GINA subgroup } \\
\text { GINA I }(\mathrm{n}, \%) \\
\text { GINA } 2(\mathrm{n}, \%) \\
\text { GINA } 3(\mathrm{n}, \%) \\
\text { GINA } 4(\mathrm{n}, \%) \\
\text { GINA } 5(\mathrm{n}, \%)\end{array}$ & $\begin{array}{l}-0.7(-42.0 \sim 53.4) \\
6(1.6) \\
29(7.5) \\
37(9.6) \\
222(57.4) \\
93(24.0)\end{array}$ \\
\hline $\begin{array}{l}\text { Anti-lgE therapy (n, \%) } \\
\text { ICS+LABA+LAMA (n, \%) } \\
\text { Theophylline (n, \%) }\end{array}$ & $\begin{array}{l}30(7.8) \\
24(6.2) \\
38(9.8)\end{array}$ \\
\hline $\begin{array}{l}\text { Severity of acute exacerbation } \\
\text { No/mild }(n, \%) \\
\text { Moderate }(n, \%) \\
\text { Severe }(n, \%)\end{array}$ & $\begin{array}{l}166(42.9) \\
89(23.0) \\
132(34.1)\end{array}$ \\
\hline $\begin{array}{l}\text { Annual frequency of acute exacerbation (time/year) } \\
\text { Polycyclic aromatic hydrocarbons ( } \mathrm{ng} / \mathrm{m}^{3} / \text { year) }\end{array}$ & $\begin{array}{l}0.3(0-12) \\
\text { I.I }(0.7-2.4)\end{array}$ \\
\hline
\end{tabular}

Note: Data expressed as median and range.

Abbreviations: BMI, body mass index; $\mathrm{FEV}_{\mathrm{l}}$, forced expiratory volume in the first second; FVC, forced vital capacity; ICS, inhaled corticosteroids; LABA, long-acting beta $_{2}$ agonist; IgE, immunoglobulin E; LAMA, long-acting anticholinergic antagonist. 
Table 2 Clinical Characteristics of Asthmatic Patients Based on GINA Step Treatment Subgroups

\begin{tabular}{|c|c|c|c|c|c|c|}
\hline Variables & $\begin{array}{l}\text { GINA I } \\
n=6\end{array}$ & $\begin{array}{l}\text { GINA } 2 \\
n=29\end{array}$ & $\begin{array}{l}\text { GINA } 3 \\
n=37\end{array}$ & $\begin{array}{l}\text { GINA } 4 \\
n=222\end{array}$ & $\begin{array}{l}\text { GINA } 5 \\
n=93\end{array}$ & p-value \\
\hline Age, years & $50.5(30-63)$ & $49(18-93)$ & $52.5(\mid 8-85)$ & $62(19-93)$ & $64(28-92)$ & 0.004 \\
\hline Gender, male (n, \%) & $2(33.3)$ & $12(41.4)$ & $16(43.2)$ & $116(52.3)$ & $61(65.6)$ & 0.04 \\
\hline Current/ever smokers (n, \%) & $5(83.3)$ & $4(13.8)$ & 7 (18.9) & $45(20.3)$ & $29(31.2)$ & 0.003 \\
\hline $\mathrm{BMI}\left(\mathrm{Kg} / \mathrm{m}^{2}\right)$ & $25.7(21.0-28.7)$ & $23.6(18.1-34.4)$ & $24.4(18.3-37.8)$ & $24.8(\mid 7.5-38.1)$ & $24.3(16.6-37.7)$ & 0.35 \\
\hline Atopic (n, \%) & $2(33.3)$ & $23(82.1)$ & $23(62.2)$ & $134(6 \mid .5)$ & $59(64.1)$ & 0.14 \\
\hline IgE level (IU/mL) & $70.6(2.7-1001)$ & $155(0-3085.9)$ & $85.9(2-5000)$ & $99.4(0-3085.9)$ & $125.5(2-5000)$ & 0.5 \\
\hline Non-compliance of medication ( $\mathrm{n}, \%)$ & $4(66.7)$ & II (37.9) & $12(32.4)$ & $69(31.1)$ & $20(21.5)$ & 0.08 \\
\hline \multicolumn{7}{|l|}{ Pulmonary function test } \\
\hline FVC (L) & $2.6(2.4-3.4)$ & $2.7(0.5-4.7)$ & $2.4(1.2-5.1)$ & $2.1(0.4-5.0)$ & $2.1(0.5-4.9)$ & 0.0008 \\
\hline FVC (\% predicted) & $85(75-108)$ & $84(40-122)$ & $86(44-125)$ & $75(15-161)$ & $72(19-134)$ & 0.002 \\
\hline FEV $_{\text {, (L) }}$ & $2.1(1.6-2.3)$ & $2.1(0.4-4.0)$ & $1.8(0.5-3.1)$ & $1.5(0.4-4.2)$ & $1.3(0.3-3.6)$ & $<0.0001$ \\
\hline FEV (\%predicted) & $78.5(67-94)$ & $78(49-118)$ & $74(25-108)$ & $70(22-156)$ & $55(17-123)$ & $<0.0001$ \\
\hline $\mathrm{FEV}_{\mathrm{I}} / \mathrm{FVC}$ ratio (\%) & $75.9(63-85)$ & $78.9(59-64.6)$ & $73.2(40.6-99)$ & $73.7(35.2-100)$ & $63.8(24.0-91.2)$ & $<0.0001$ \\
\hline $\begin{array}{l}\text { Frequency of any acute exacerbation } \\
\text { (times/year) }\end{array}$ & $0.5(0-3)$ & $0(0-3.3)$ & $0(0-3)$ & $0.3(0-4.5)$ & $1(0-12)$ & $<0.0001$ \\
\hline \multicolumn{7}{|l|}{ Acute exacerbation severity } \\
\hline Non-severe acute exacerbation (n, \%) & $5(83.3)$ & $21(72.4)$ & $28(75.7)$ & 157 (7I.3) & $44(47.3)$ & \\
\hline Severe acute exacerbation ( $n, \%)$ & I (16.7) & $8(27.6)$ & $9(24.3)$ & $65(29.3)$ & $49(52.7)$ & \\
\hline $\begin{array}{l}\text { Polycyclic aromatic hydrocarbons } \\
\left(\mathrm{ng} / \mathrm{m}^{3} / \text { year) }\right.\end{array}$ & I.3 (I.0-I.4) & I.I (0.9-1.6) & I.I (0.9-1.6) & I.I (0.7-2.4) & I (0.9-I.7) & 0.42 \\
\hline
\end{tabular}

Note: Data expressed as median and range.

Abbreviations: BMI, body mass index; $\mathrm{FEV}_{1}$, forced expiratory volume in the first second; FVC, forced vital capacity.

of non-compliance and annual exposure of PAHs ( $\mathrm{ng} / \mathrm{m}^{3} /$ year) between these GINA subgroups (Table 2).

\section{Associations Between Clinical Parameters and Annual Acute Exacerbation Frequency or Annual Exposure of PAHs}

There was a significant positive correlation between annual concentration of PAHs and the annual frequency of any acute exacerbation $(r=0.11, p=0.02)$ (Figure 3$)$. In clinical parameters, the annual frequency of any acute exacerbation was highly correlated with the annual exposure concentration of PAHs, GINA step treatment subgroups, and the acute exacerbation severity (Table 3). The covariates with a significant relationship with annual exacerbation frequency were included for multivariable regression analysis. We found that the annual cumulative exposure of PAHs, GINA step treatment and the severity of exacerbation were the independent variables to predict annual exacerbation frequency $\left(\mathrm{r}^{2}=0.42, \mathrm{p}<0.0001\right)$ (Table 4).

\section{Relationship Between Annual Frequency of Acute Exacerbation and Annual Exposure Concentration of PAHs in GINA 5 Subgroup}

The annual exposure to PAHs was highly correlated with the annual frequency of any exacerbation in the GINA 5 subgroup $(R=0.29$ and $p=0.005)$ (Figure $4 A)$. The correlation of the annual exposure concentration of PAHs and the annual frequency of severe acute exacerbation was more significant in patients who were in GINA step5 subgroup $(r=0.51, p=0.002)$ (Figure 4B). However, there was no association between the annual exposure concentration of PAHs and the annual frequency of non-severe acute exacerbation in asthmatic patients with GINA step5 treatment (Figure 4C). Otherwise, the annual exposure concentration of PAHs against the annual frequency of any/severe/nonsevere acute exacerbation showed no significant correlations in asthmatic patients with GINA step 1 to 4 subgroups, respectively (See Supplemental Figure 1). 


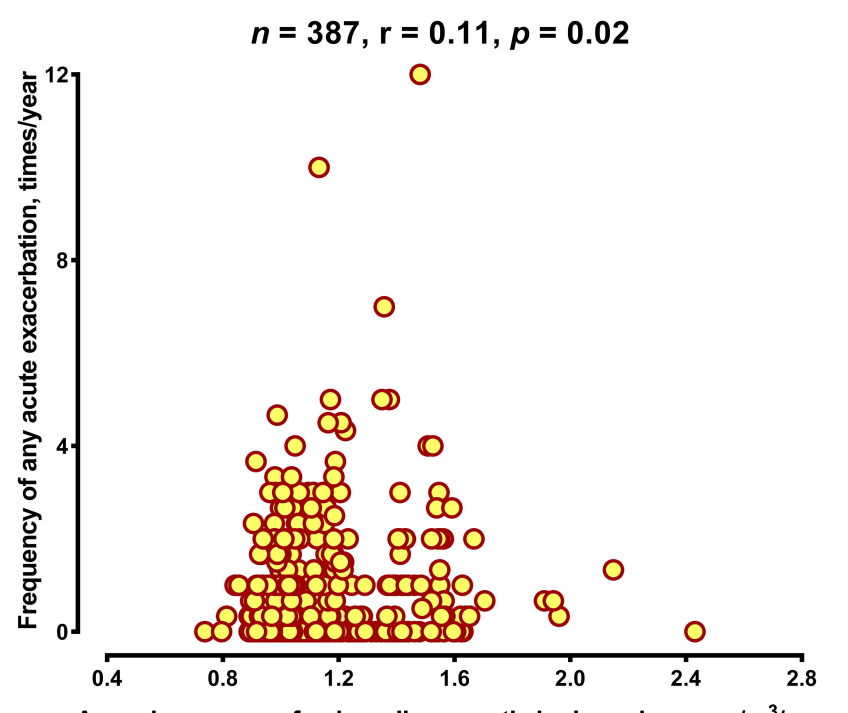

Annual exposure of polycyclic aromatic hydrocarbons, $\mathrm{ng} / \mathrm{m}^{3} / \mathrm{year}$

Figure 3 Scatterplot of the annual exposure concentration of polycyclic aromatic hydrocarbons ( $\mathrm{ng} / \mathrm{m}^{3} /$ year) against the annual frequency of any acute exacerbation in asthmatic patients (time/year).

\section{Discussion}

We demonstrated that the annual exposure concentration of PAHs, GINA step treatment subgroups and acute exacerbation severity were independent variables that were highly correlated with the annual frequency of any exacerbation. Based on the GINA step treatment, the more severe group of GINA step 5 asthmatic patients were older, with decreased lung function, higher annual frequency of any acute exacerbation, and with more severe acute exacerbations. Using the grid-scale model for simulating hourly $\mathrm{PM}_{2.5} \mathrm{PAH}$ concentrations, we determined the annual exposure concentration of PAHs in these patients with asthma. We found that the annual exposure concentration of PAHs was correlated to the annual frequency of severe acute exacerbation in the patients with asthma in GINA 5 subgroup. However, the association of the annual exposure concentration of PAHs and the annual frequency of non-severe acute exacerbation was not observed in those of GINA 5 asthmatic patients.

Correlation of disease severity according to GINA strategy among higher annual frequency of any exacerbation has been confirmed. ${ }^{25}$ Our results are compatible with a previous study of more than 200,000 asthmatic patients in the US and UK that reported the annual exacerbation frequency in GINA step5 subgroup as nearly 3-fold higher than the other subgroups. ${ }^{23}$ Even for those groups exposed to similar concentration of PAHs, there was also a greater correlation between the annual acute exacerbation frequency and the annual exposure concentration of PAHs in the more severe GINA step5 subgroup. Our study is the first report to evaluate the impact of ambient PAHs on different GINA subgroups used as a measure of asthma severity and suggests that patients in GINA 5 subgroup were more susceptible to PAHs exposure. Our data therefore support the avoidance of exposure to high levels of PAHs particularly in GINA step5 patients in whom the resulting clinical benefit would be most felt.

An increased risk of acute asthma exacerbation associated with air pollutants has been previously reported, ${ }^{33-37}$ with varying severity of exacerbation ranging from easily controlled symptoms to those needing hospitalization. McConnell et al reported that symptoms of bronchitis increased in proportion to the concentration of organic carbon (OC), and particular matter 2.5 (PM2.5), and the levels of gaseous $\mathrm{NO}_{2}$ and $\mathrm{O}_{3}$ in asthmatic children. ${ }^{33}$ A study in Singapore observed that severe acute exacerbation with emergency department visit was associated with air pollutant level particularly sulfur dioxide $\left(\mathrm{SO}_{2}\right)$ and the numbers of total suspended particles (TSP) in asthmatic children.34 Furthermore, ambient air pollution was associated with

Table 3 Correlations of Clinical Parameters and Annual Frequency of Any Acute Exacerbation

\begin{tabular}{|l|l|l|}
\hline Variables & r value & p value \\
\hline Age & 0.14 & 0.07 \\
Gender (male vs female) & 0.03 & 0.61 \\
BMI (kg/m²) & 0.02 & 0.71 \\
Smoking (current/ever smokers vs non-smokers) & 0.001 & 0.98 \\
Allergy (atopic vs non-atopic) & -0.02 & 0.08 \\
Baseline IgE level & 0.01 & 0.78 \\
Compliance (non-compliance vs compliance) & 0.06 & 0.23 \\
GINA stepl-5 & 0.21 & $<0.0001$ \\
Acute exacerbation severity (severe vs non-severe) & 0.64 & $<0.0001$ \\
Polycyclic aromatic hydrocarbons (ng/m $/$ /year) & 0.11 & 0.02 \\
\hline
\end{tabular}

Abbreviations: BMI, body mass index; GINA, Global Initiative of Asthma. 
Table 4 Multivariable Regression Model for Annual Frequency of Any Acute Exacerbation

\begin{tabular}{|l|l|l|l|l|}
\hline Variables & Beta & SE & t value & P value \\
\hline Polycyclic aromatic hydrocarbons (PAHs, ng/m $/$ /year) & 0.69 & 0.23 & 2.93 & 0.004 \\
Acute exacerbation severity & 1.67 & 0.11 & 15.54 & $<0.0001$ \\
GINA step treatment subgroups & 0.16 & 0.06 & 2.69 & 0.007 \\
\hline
\end{tabular}

Notes: $r^{2}=0.42$ adjusted $r^{2}=0.42$, Residual standard error $=0.99, p<0.0001$.

Abbreviation: SE, standard error of beta.

hospital admission for asthmatic patients who are less than 65 years old in Seattle, US. ${ }^{38}$ In this study area, Taipei City, Yang et al indicated that the risk of hospital admissions for asthma increased when ambient air pollutant (including $\mathrm{SO}_{2}$,
$\mathrm{NO}_{2}, \mathrm{CO}$ and $\mathrm{O}_{3}$ ) concentrations were higher. ${ }^{21}$ However, there is no literature on the link between ambient PAHs concentrations and exacerbation frequency of different severities. We demonstrated that severe acute exacerbation was
A
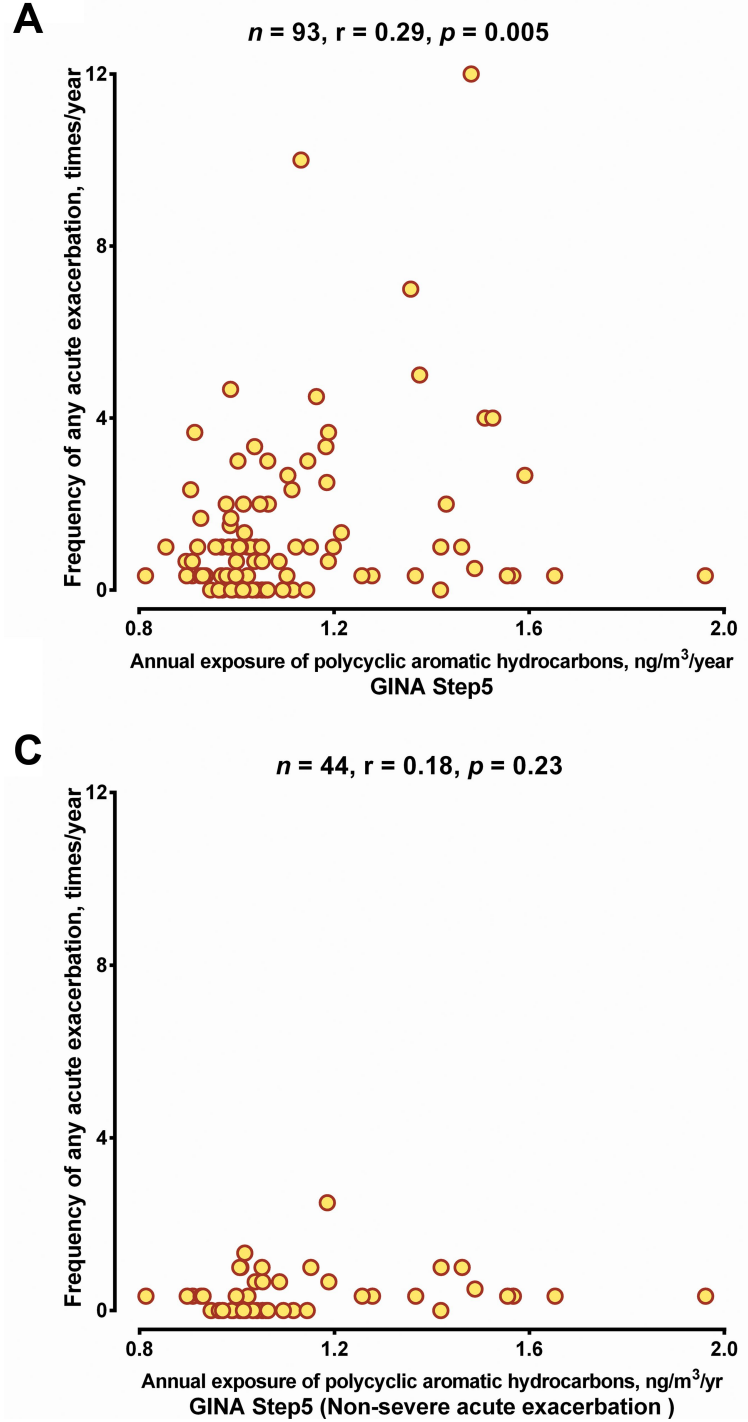

B

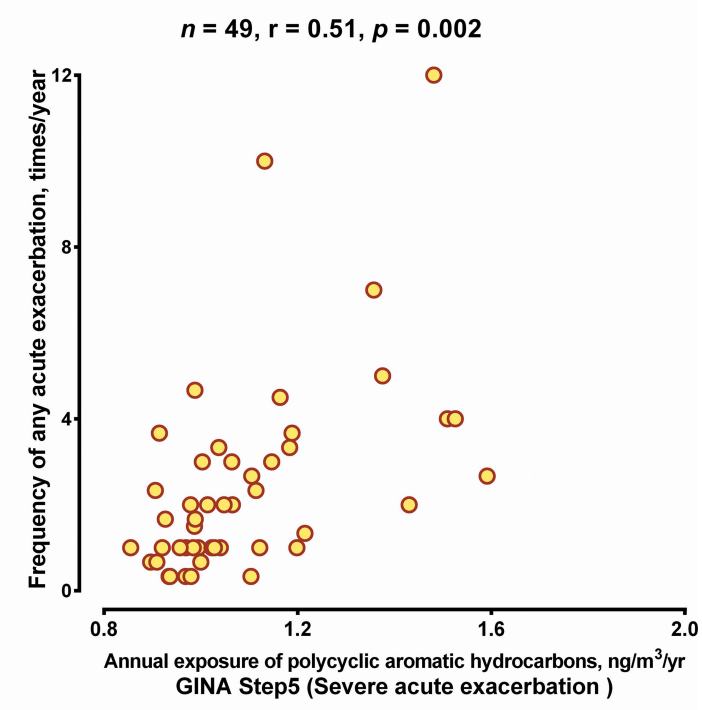

Figure 4 (A) Scatterplot of the annual exposure concentration of polycyclic aromatic hydrocarbons (ng/m $\left.{ }^{3} / y e a r\right)$ against the annual frequency of any acute exacerbation (time/year) in asthmatic patients who were in GINA 5 subgroup. (B) Scatterplot of the annual exposure concentration of polycyclic aromatic hydrocarbons (ng/m $\left.{ }^{3} / y e a r\right)$ against the annual frequency of severe acute exacerbation in asthmatic patients (time/year) who were in GINA 5 subgroup (C) Scatterplot of the annual concentration of polycyclic aromatic hydrocarbons ( $\mathrm{ng} / \mathrm{m}^{3} /$ year) against the annual frequency of any non-severe acute exacerbation (time/year) in asthmatic patients who were in GINA 5 subgroup. $P$ value is indicated. 
an independent variable that was correlated with acute exacerbation frequency. Besides, patients in GINA 5 subgroup with severe acute exacerbation were more susceptible to ambient PAHs.

Due to the heavy vehicular traffic and the poor dispersion of atmospheric pollutants, relatively high concentrations of atmospheric PAHs are usually found in urban areas. ${ }^{39}$ The possible mechanisms underlying the induction of exacerbations by PAHs which are considered as outdoor pollutants remain unclear. PAHs may impair the airway epithelium, ${ }^{40}$ activate inflammatory factors from the airway epithelium, ${ }^{41}$ that could contribute to the pathogenesis of the acute exacerbation. ${ }^{42}$ In addition, epithelium dysfunction was observed in severe asthma of GINA step5 and resulted in release of cytokines, such as IL-25, IL-33, thymic stromal lymphopoietin (TSLP) and IL-17A, from an injured epithelium. These cytokines could contribute to eosinophilic airway inflammation and bronchial hyperreactivity. ${ }^{43,44}$ Exposure to PAHs, such as benzo[a]pyrene, may activate aryl hydrocarbon receptor (AhR) in epithelial cells leading to an enhancement in the production of epithelium-derived cytokines that could contribute to ${ }^{\text {an }}$ increase in the rate of severe exacerbations. ${ }^{45,46}$ Therefore, different severity of acute exacerbation may present with varying degrees of damaged airway epithelium, that may underlie the differential susceptibility to the toxicity of PAHs.

There are limitations in our study. First, the socioeconomic status has been reported to be associated with air pollution on the health effects. ${ }^{47,48}$ In this study, we did not evaluate the relationship among the annual concentration of PAHs and the acute exacerbation frequency under different socioeconomic status. Future studies to explore the possibility of confounders of the air pollution-socioeconomic status association will be performed. Secondly, we evaluated the effects of PAHs exposure cumulatively but not in a time-stratified case-crossover design. Otherwise, limited by the retrospective nature of our data, we did not identify the exact timing of the episode of acute exacerbation in each patient. We could not report the short-term or seasonal effects of PAHs exposure. Thirdly, outdoor pollutants almost always occur as a mixture. Several outdoor pollutants, such as ozone, nitrogen dioxide, sulfur dioxide, have been associated with asthma exacerbation in the short-term exposure. We did not adjust these components in this study. Therefore, there were no comparative results of outdoor pollutants other than PAHs associated with acute exacerbation. Finally, our study did not examine the link between the inflammatory factors and the PAHs influencing the acute asthma exacerbation. It would therefore be interesting to evaluate the biological and molecular mechanisms of PAHs' on acute exacerbations at the different levels of severity of asthma.

\section{Conclusion}

We found a significant correlation between the annual exacerbation frequency and the annual exposure of polycyclic aromatic hydrocarbons in asthmatic patients. This association was more prominent in the more severe patients with severe acute exacerbations. Control of environmental air pollution level to reduce the frequency of exacerbations will benefit particularly the more severe asthma patient.

\section{Abbreviations}

$\mathrm{AE}$, acute exacerbation; AhR, aryl hydrocarbon receptor; CWB, Central Weather Bureau; EPA, environmental protection agency (EPA); $\mathrm{FEV}_{1}$, forced expiration volume in the first second; GINA, Global Initiative of Asthma; GIS, Geographic information system; ICS, inhaled corticosteroids; SABA, short-acting beta2 agonist; LABA, longacting beta2 agonist; MLR, multivariate linear regression; $\mathrm{NO}_{2}$, nitrogen dioxide; PM, particulate matter; OC, organic carbon; OCS, oral corticosteroids; $\mathrm{O}_{3}$, Ozone; $\mathrm{SO}_{2}$, sulfur dioxide; PAHs, polycyclic aromatic hydrocarbons; TSLP, thymic stromal lymphopoietin.

\section{Data Sharing Statement}

The data sets analyzed during the current study are available from the corresponding author upon reasonable request.

\section{Acknowledgment}

We thank all the investigators and members of the Department of Thoracic Medicine for their effort.

\section{Author Contributions}

All authors contributed substantially to the concept and design, data analysis and interpretation, to the drafting or critical revision of the article, have agreed to submit the article to the current journal, gave final approval of the version to be published, and agree to be accountable for all aspects of the work.

\section{Funding}

This work was supported by the Ministry of Science and Technology Research grants (MOST107-2314-B-182-074MY3, MOST105-EPA-F-008-001 and MOST108-2611M-110-008) and the Chang Gung Medical Research Project grants (CMRPG3F1501 and CMRPG3F1502). 


\section{Disclosure}

The authors report no conflicts of interest in this work.

\section{References}

1. Holloway JW, Savarimuthu FS, Fong KM, et al. Genomics and the respiratory effects of air pollution exposure. Respirology. 2012;17 (4):590-600. doi:10.1111/j.1440-1843.2012.02164.x

2. Laden F, Schwartz J, Speizer FE, et al. Reduction in fine particulate air pollution and mortality: extended follow-up of the Harvard Six Cities study. Am J Respir Crit Care Med. 2006;173(6):667-672. doi:10.1164/rccm.200503-443OC

3. Organization WH. Global Status Report on Alcohol and Health 2018. World Health Organization; 2019.

4. Kim KH, Jahan SA, Kabir E, et al. A review of airborne polycyclic aromatic hydrocarbons (PAHs) and their human health effects. Environ Int. 2013;60:71-80. doi:10.1016/j.envint.2013.07.019

5. Karimi P, Peters KO, Bidad K, et al. Polycyclic aromatic hydrocarbons and childhood asthma. Eur J Epidemiol. 2015;30(2):91-101. doi:10.1007/s10654-015-9988-6

6. Bostrom CE, Gerde P, Hanberg A, et al. Cancer risk assessment, indicators, and guidelines for polycyclic aromatic hydrocarbons in the ambient air. Environ Health Perspect. 2002;110(3):451-488. doi:10.1289/ehp.110-1241197

7. Srogi K. Monitoring of environmental exposure to polycyclic aromatic hydrocarbons: a review. Environ Chem Lett. 2007;5 (4):169-195. doi:10.1007/s10311-007-0095-0

8. D'Amato G, Baena-Cagnani CE, Cecchi L, et al. Climate change, air pollution and extreme events leading to increasing prevalence of allergic respiratory diseases. Multidiscip Respir Med. 2013;8(1):12. doi:10.1186/2049-6958-8-12

9. Ierodiakonou D, Zanobetti A, Coull BA, et al. Ambient air pollution, lung function, and airway responsiveness in asthmatic children. $J$ Allergy Clin Immunol. 2016;137(2):390-399. doi:10.1016/j. jaci.2015.05.028

10. Patel MM, Chillrud SN, Deepti KC, et al. Traffic-related air pollutants and exhaled markers of airway inflammation and oxidative stress in New York City adolescents. Environ Res. 2013;121:71-78. doi:10.1016/j.envres.2012.10.012

11. Pauk N, Klimesova S, Kara J, et al. The relevance of monitoring of antibodies against the polycyclic aromatic hydrocarbon $(\mathrm{PAH})$ and PAH-DNA adducts in serum in relation to lung cancer and chronic obstructive pulmonary disease (COPD). Neoplasma. 2013;60 (2):182-187. doi:10.4149/neo_2013_024

12. Zhang $\mathrm{Y}$, Tao $\mathrm{S}$, Shen $\mathrm{H}$, et al. Inhalation exposure to ambient polycyclic aromatic hydrocarbons and lung cancer risk of Chinese population. Proc Natl Acad Sci U S A. 2009;106(50):21063-21067. doi:10.1073/pnas.0905756106

13. Guarnieri M, Balmes JR. Outdoor air pollution and asthma. Lancet. 2014;383(9928):1581-1592. doi:10.1016/S0140-6736(14)60617-6

14. Wong TH, Lee CL, Su HH, et al. A prominent air pollutant, Indeno [1, 2, 3-cd] pyrene, enhances allergic lung inflammation via aryl hydrocarbon receptor. Sci Rep. 2018;8(1):1-11. doi:10.1038/s41598-018-23542-9

15. Organization. Global strategy for asthma management and prevention. 2020.

16. Bowatte G, Lodge C, Lowe AJ, et al. The influence of childhood traffic-related air pollution exposure on asthma, allergy and sensitization: a systematic review and a meta-analysis of birth cohort studies. Allergy. 2015;70(3):245-256. doi:10.1111/all.12561

17. Strickland MJ, Darrow LA, Klein M, et al. Short-term associations between ambient air pollutants and pediatric asthma emergency department visits. Am J Respir Crit Care Med. 2010;182 (3):307-316. doi:10.1164/rccm.200908-1201OC
18. Li S, Batterman S, Wasilevich E, et al. Association of daily asthma emergency department visits and hospital admissions with ambient air pollutants among the pediatric Medicaid population in Detroit: time-series and time-stratified case-crossover analyses with threshold effects. Environ Res. 2011;111(8):1137-1147. doi:10.1016/j.envres.2011.06.002

19. Hsu SH, Chang JH, Lee CL, et al. Differential time-lag effects of ambient PM 2.5 and PM 2.5-bound PAHs on asthma emergency department visits. Environ Sci Pollut Res. 2020;1-8.

20. Bell ML, Levy JK, Lin Z. The effect of sandstorms and air pollution on cause-specific hospital admissions in Taipei, Taiwan. Occup Environ Med. 2008;65(2):104-111. doi:10.1136/oem.2006.031500

21. Yang CY, Chen CC, Chen CY, et al. Air pollution and hospital admissions for asthma in a subtropical city: taipei, Taiwan. J Toxicol Environ Health Part A. 2007;70(2):111-117. doi:10.1080/ 15287390600755059

22. Delfino RJ, Zeiger RS, Seltzer JM, et al. Association of asthma symptoms with peak particulate air pollution and effect modification by anti-inflammatory medication use. Environ Health Perspect. 2002;110(10):607-617. doi:10.1289/ehp.021100607

23. Li N, Wang M, Bramble LA, et al. The adjuvant effect of ambient particulate matter is closely reflected by the particulate oxidant potential. Environ Health Perspect. 2009;117(7):1116-1123. doi: 10.1289/ehp.0800319

24. Vattanasit U, Navasumrit P, Khadka MB, et al. Oxidative DNA damage and inflammatory responses in cultured human cells and in humans exposed to traffic-related particles. Int J Hyg Environ Health. 2014;217(1):23-33. doi:10.1016/j.ijheh.2013.03.002

25. Suruki RY, Daugherty JB, Boudiaf N, et al. The frequency of asthma exacerbations and healthcare utilization in patients with asthma from the UK and USA. BMC Pulm Med. 2017;17(1):74. doi:10.1186/ s12890-017-0409-3

26. Lee CL, Huang HC, Wang CC, et al. A new grid-scale model simulating the spatiotemporal distribution of PM2.5-PAHs for exposure assessment. J Hazard Mater. 2016;314:286-294. doi:10.1016/j. jhazmat.2016.04.047

27. Society AT. Standards for the diagnosis and care of patients with chronic obstructive pulmonary disease (COPD) and asthma. Am Rev Respir Dis. 1987;136:225-244.

28. Stridsman C, Axelsson M, Warm K. et al. Uncontrolled asthma occurs in all GINA treatment steps and is associated with worse physical health - a report from the OLIN adult asthma cohort. J Asthma;2020. 1-10. doi:10.1080/02770903.2020.1713150

29. Belanger K, Holford TR, Gent JF, et al. Household levels of nitrogen dioxide and pediatric asthma severity. Epidemiology (Cambridge, Mass). 2013;24(2):320. doi:10.1097/EDE.0b013e318280e2ac

30. Kasumagic HE, Prohic A. Serum levels of total immunoglobulin e in patients with alopecia areata: relationship with clinical type of the disease. Acta Dermatovenerol Croat. 2006;14(3):149-152.

31. Kim JL, Henneberger PK, Lohman S, et al. Impact of occupational exposures on exacerbation of asthma: a population-based asthma cohort study. BMC Pulm Med. 2016;16(1):148. doi:10.1186/s12890-016-0306-1

32. Hsieh MT, Peng CY, Chung WY, et al. Simulating the spatiotemporal distribution of BTEX with an hourly grid-scale model. Chemosphere. 2020;246:125722. doi:10.1016/j.chemosphere.2019.125722

33. McConnell R, Berhane K, Gilliland F, et al. Prospective study of air pollution and bronchitic symptoms in children with asthma. Am $J$ Respir Crit Care Med. 2003;168(7):790-797. doi:10.1164/ rccm.200304-466OC

34. Chew F, Goh D, Ooi B, et al. Association of ambient air-pollution levels with acute asthma exacerbation among children in Singapore. Allergy. 1999;54(4):320-329. doi:10.1034/j.1398-9995.1999.00012.x

35. Trasande L, Thurston GD. The role of air pollution in asthma and other pediatric morbidities. J Allergy Clin Immunol. 2005;115 (4):689-699. doi:10.1016/j.jaci.2005.01.056 
36. Ko FW, Tam W, Wong TW, et al. Effects of air pollution on asthma hospitalization rates in different age groups in Hong Kong. Clin Exp Immunol. 2007;37(9):1312-1319.

37. Tarlo SM, Broder I, Corey P, et al. The role of symptomatic colds in asthma exacerbations: influence of outdoor allergens and air pollutants. J Allergy Clin Immunol. 2001;108(1):52-58. doi:10.1067/mai.2001.116574

38. Sheppard L, Levy D, Norris G, et al. Effects of ambient air pollution on nonelderly asthma hospital admissions in Seattle, Washington, 1987-1994. Epidemiology (Cambridge, Mass). 1999;10(1):23-30. doi:10.1097/00001648-199901000-00006

39. Chang KF, Fang GC, Chen JC, Wu YS. Atmospheric polycyclic aromatic hydrocarbons (PAHs) in Asia: a review from 1999 to 2004. Environ Pollut. 2006;142(3):388-396. doi:10.1016/j. envpol.2005.09.025

40. Rummel AM, Trosko JE, Wilson MR, et al. Polycyclic aromatic hydrocarbons with bay-like regions inhibited gap junctional intercellular communication and stimulated MAPK activity. J Toxicol Sci. 1999;49(2):232-240. doi:10.1093/toxsci/49.2.232

41. Leem JH, Kim JH, Lee KH, et al. Asthma attack associated with oxidative stress by exposure to ETS and PAH. J Asthma. 2005;42 (6):436-437. doi:10.1080/02770900500200733

42. Holgate ST, Roberts G, Arshad HS, et al. The role of the airway epithelium and its interaction with environmental factors in asthma pathogenesis. Proc Am Thorac Soc. 2009;6(8):655-659. doi:10.1513/ pats.200907-072DP
43. Hurrell BP, Shafiei Jahani P, Akbari O. Social networking of group two innate lymphoid cells in allergy and asthma. Front Immunol. 2018;9:2694. doi:10.3389/fimmu.2018.02694

44. Huang YC, Weng CM, Lee MJ, et al. Endotypes of severe allergic asthma patients who clinically benefit from anti-IgE therapy. Clin Exp Immunol. 2019;49(1):44-53.

45. Michaelson JJ, Trump S, Rudzok S, et al. Transcriptional signatures of regulatory and toxic responses to benzo-[a]-pyrene exposure. $B M C$ Genomics. 2011;12:502. doi:10.1186/1471-2164-12-502

46. Wang E, Liu X, Tu W, et al. Benzo(a)pyrene facilitates dermatophagoides group 1 (Der f 1)-induced epithelial cytokine release through aryl hydrocarbon receptor in asthma. Allergy. 2019;74(9):1675-1690. doi:10.1111/all.13784

47. Stroh E, Oudin A, Gustafsson S, et al. Are associations between socio-economic characteristics and exposure to air pollution a question of study area size? An example from Scania, Sweden. Int $J$ Health Geogr. 2005;4(1):30. doi:10.1186/1476-072X-4-30

48. Pratt GC, Vadali ML, Kvale DL, Ellickson KM. Traffic, Air pollution, minority and socio-economic status: addressing inequities in exposure and risk. Int $J$ Environ Res Public Health. 2015;12 (5):5355-5672. doi:10.3390/ijerph120505355

\section{Publish your work in this journal}

The Journal of Asthma and Allergy is an international, peer-reviewed open-access journal publishing original research, reports, editorials and commentaries on the following topics: Asthma; Pulmonary physiology; Asthma related clinical health; Clinical immunology and the immunological basis of disease; Pharmacological interventions and new therapies. The manuscript management system is completely online and includes a very quick and fair peer-review system, which is all easy to use. Visit http://www.dovepress.com/testimonials.php to read real quotes from published authors. 